\title{
Effectiveness of Application of PLISSIT Counseling Model on Sexuality for Breast Cancer's Women Undergoing Treatment
}

\author{
Nabila El- Sayed Saboula ${ }^{1, *}$, Marwa Ahmed Shahin ${ }^{2}$ \\ ${ }^{1}$ Community Health Nursing Department, Faculty of Nursing, Menoufia University, Shebin Elkom, Egypt \\ ${ }^{2}$ Maternal \& Newborn Health Nursing Department, Faculty of Nursing, Menoufia University, Shebin Elkom, Egypt
}

Email address:

nabilasabola@yahoo.com (N. El- Sayed Saboula),mrmr.shahin@yahoo.com (M. A. Shahin)

\section{To cite this article:}

Nabila El- Sayed Saboula, Marwa Ahmed Shahin. Effectiveness of Application of PLISSIT Counseling Model on Sexuality for Breast Cancer's Women Undergoing Treatment. American Journal of Nursing Science. Vol. 4, No. 4, 2015, pp. 218-230.

doi: 10.11648/j.ajns.20150404.21

\begin{abstract}
Background: A breast cancer's diagnosis and treatment can bring changes related to women's body image and sexuality, which can have a devastating impact on intimate relationships and sexuality. The study aim to examine the effectiveness of PLISSIT Counseling Model on female sexuality, body image and couple satisfaction for breast cancer women undergoing treatment. Subjects \&methods a quasi-experimental design was used. The study was conducted at Out-patient Oncology Institute, Menoufia University-Egypt. A purposive sample of 66 women with breast cancer was included. Four tools were used to collect data., a structured interviewing questionnaire, body image scale, female sexual function index (FSDI), the revised dyadic adjustment scale. Results. A significant relationship was found between treatment side effects pre and post intervention regarding nausea $\&$ vomiting, diarrhea and pain. The mean score of body image, couple satisfaction and sexual dysfunction were improved after application of PLISST counseling model. Conclusion: application of PLISSIT model was effective in enhancing sexual functioning, body image and couple satisfaction for breast cancer women under treatment regimen. Recommendation: Adopting PLISSIT sexual counseling model in addressing sexual dysfunction in a cancer treatment institutions. Applying the evidence -based nursing interventions to address and manage the effects of breast cancer on sexuality.
\end{abstract}

Keywords: Breast Cancer, Sexuality, Body Image, Couple Satisfaction, PLISSIT Model

\section{Introduction}

Breast cancer is the most common cancer in women both in the developed and less developed world. It is estimated that worldwide over 508, 000 women died in 2011 due to breast cancer. Although breast cancer is thought to be a disease of the developed world, almost $50 \%$ of breast cancer cases and $58 \%$ of deaths occur in less developed countries. ${ }^{[1]}$ Incidence rates of breast cancer vary greatly worldwide from 19.3 per 100,000 women in Eastern Africa to 89.7 per 100,000 women in Western Europe. In 2012, 1.7 million women were diagnosed with breast cancer. Since the 2008 estimates, breast cancer incidence has increased by more than $20 \%$, while mortality has increased by $14 \%$. Globally, approximately, $20 \%-30 \%$ of breast cancer survivors experience sexuality problems which include general sexual disruptions, decrease frequency of intercourse and difficulties reaching orgasm. ${ }^{[1]}$

In Egypt, the breast cancer incidence rates for women in 2008-2011 based upon data of the National Cancer Registry Program of Egypt was $32 \%$. ${ }^{[2]}$ The low survival rates in less developed countries can be explained mainly by the lack of early detection programs, resulting in a high proportion of women presenting with late-stage disease, as well as by the lack of adequate diagnosis and treatment facilities. ${ }^{[3]}$

Sexuality is a complex, multidimensional phenomenon that incorporates biological, psychological and behavioral part. Sexuality have feeling about one's body, the need for touch, interest in sexual activity and ability to engage in satisfying sexual activities. ${ }^{[4]}$ Sexual health problems are higher in oncology patients, especially in those with breast 
and gynecologic cancers. ${ }^{[5]}$

The term 'body image' is difficult to define, because it means different things for different people, it is defined by Grogan (2008) ${ }^{[6]}$ as: '...a person's perceptions, thoughts and feelings about his or her body'.

A breast cancer diagnosis and breast cancer treatments can bring changes related to a person's body image and sexuality, which in turn can have a devastating impact on intimate relationships. ${ }^{[7]}$

Breast cancer treatment may result in major alterations of body image through loss of a body part, disfigurement, scars or skin changes. Radiotherapy may cause tissue damage with insidious changes over many years, the effects of surgery are more immediate but often permanent, whereas transient, reversible changes (e.g. hair loss) may result from systemic chemotherapy. Thus, large numbers of patients across many disease groups and treatment types can be affected. ${ }^{[8]}$

The PLISSIT model is a tool for both assessing and managing a patient's sexuality concerns. The model was created in 1976 by Jack S. Annon. It consists of four steps for addressing the sexual concerns of cancer patients: "Permission," Limited Information," "Specific Suggestions," and "Intensive Therapy." This model offers nurses or case managers, a concise framework for intervention to address patients' concerns, and helps assure informed feedback to the healthcare team regarding the patients' sexual issues. ${ }^{[9]}$

Nurses are at the first degree, among health personnel to whom patients can easily explain themselves and can be effective in removing their concerns related sexual health. Nurses have important duties as counselor and guide in determining the factors affecting sexual functions of breast cancer patients, problems that may be experience in sexual matters, and providing help to these individuals in order to overcome these problems. ${ }^{[10]}$

\subsection{Significance of Study}

A breast cancer's diagnosis and treatment can bring changes related to women's body image and sexuality, which can have a devastating impact on intimate relationships and sexuality. A growing body of evidence suggests that difficulties with sexual functioning may be among the more common and distressing problems experienced by breast cancer women accompanied with treatment. ${ }^{[11]}$ One of the most widely accepted screening sexual models that could be useful in oncology is the PLISSIT model. The PLISSIT model is a tool for both assessing and managing a patient's sexuality concerns. It is thought that an intervention plan prepared within the framework of the PLISSIT model will guide nurses in solving sexual problems of women with cancer breast and providing integrated care and help them to express their sexual problems. ${ }^{[9]}$ As the research on sexuality and body image in relation to cancer and its treatment guided by application of PLISSIT model is quite limited so the present study was conducted to examine the effectiveness of application of PLISSIT counseling model on sexuality.

\subsection{Aim}

The aim of this study was to examine the effectiveness of PLISSIT counseling Model on sexuality including (sexual functioning, body image and couple satisfaction) for women with breast cancer undergoing treatment.

\subsection{Study Hypothesis}

Breast cancer women who have poor sexuality (sexual functioning, poor body image and bad couple satisfaction) will experience an improvement in sexuality after application of PLISSIT counseling model post intervention compared to pre intervention.

\section{Subjects and Methods}

\subsection{Study Design}

A quasi-experimental (pre-post) study design was used.

\subsection{Study Setting}

The study was conducted in Out-patient Oncology Institute, Menoufia University - Egypt.

\subsection{Subjects}

A simple random probability sample, composed of 66 women with breast cancer was included and willing to participate and complete the study.

Inclusion criteria: All married women who diagnosed with breast cancer undergoing different types of treatment, in all ages were recruited

Exclusion criteria: Gynecological tumor e.g. vaginal, cervical and uterine cancer was excluded.

Sample size Equation: at $95 \%$ confidence power of the study. The researchers depended on the following equation to calculate the sample size:

Steven Thimpsone Equation

$$
\mathrm{n}=\frac{\mathrm{N} \times \mathrm{P}(1-\mathrm{P})}{(\mathrm{N}-1 \times(\mathrm{d} 2 / \mathrm{Z} 2))+\mathrm{P}(1-\mathrm{P})}
$$

$\mathrm{n}=$ Sample size

$\mathrm{N}=$ Total society size $=180$

$\mathrm{d}=$ error percentage $=(0.05)$

$\mathrm{P}=$ percentage of availability of the character and

Objectivity $=(0.1)$

$Z=$ the corresponding standard class of significance $95 \%=$ (1.96)

$\mathrm{n}=180 \times(0.1 \times 0.9) / 179 \times 0.052 / 1.962+(0.1 \times 0.9)$

$\mathrm{n}=180 \times 0.09 / 179 \times 0.002 / 3.84+0.09$

$\mathrm{n}=16.2 / 0.19=85$

Sample size $=85$

Out of them 19 breast cancer women not continue to complete the study and dropped from the total sample which became 66 women only. So, the final sample size was 66 . 


\subsection{Study Tools}

Tool I.A Structured interviewing questionnaire developed by the researchers which included the following data:

A. Basic data of studied women including age, duration of marriage, education, occupation and residence, income.

B. Menstrual / obstetric / and contraceptive history.

C. Present medical history about breast cancer including how woman discovered breast cancer, onset of disease, stages of breast cancer, type of breast cancer treatment, onset of Treatment, side effect of treatment

Tool II. Female Sexual Function Index (FSDI) ${ }^{[12]}$ : A Multidimensional self - report instrument for the assessment of female sexual function. It consists of 19 - item questionnaire. It provide scores on six domains of sexual Function ; ( desire, arousal, lubrication, orgasm, satisfaction, and pain), through this tool the data about a total score can be obtained. The scale was translated into Arabic language

Tool III. Body Image Scale ${ }^{[8]}$ : It is a self - report measure of the women body image. This10-item scale was constructed in collaboration with the European Organization for Research and Treatment of Cancer (EORTC). The scale showed a high reliability (Cronbach's alpha 0.93) and good clinical validity. Scores on the body image range from 9 to 36 . Good level was 9-17, considerable level was 18-26 and bad level was 27-36. Lower scores indicate greater level of body image. The scale was translated into Arabic language.

Tool IV.The Revised Dyadic Adjustment Scale (RDAS): ${ }^{[13]}$ It is a self report questionnaire about women and her husband's adjustment and satisfaction (it taken form women opinion). It assesses seven dimensions of couple relationships quality and satisfaction within three overarching categories including consensus in decision making, values and affection, satisfaction in the relationship with respect to stability and conflict regulation, and Cohesion. It included only 14 items, each of which asks the respondents to rate certain aspects of her/his relationship on a 5 or 6 point scale. Scores on the RDAS range from 0 to 69 with higher scores indicating greater relationship satisfaction and lower scores indicating greater relationship distress. The cut-off score for the RDAS is 48 such that scores of 48 and above indicate non-distress and scores of 47 and below indicate marital/relationship distress. The scale was translated into Arabic language.

Validity of the tools: The validity of the tools was ascertained by a group of subject area experts, medical and nursing staff who reviewed the instruments for content accuracy. Also, they were asked to judge the items for completeness and clarity. Suggestions and modifications were considered.

Reliability of the tools: Test-retest reliability was applied by the researcher for testing the internal consistency of the tools. It refers to the administration of the same tools to the same subjects under similar conditions on two or more occasions. Scores from repeated testing were compared.

\subsection{Pilot Study}

Pilot study was carried out before starting data collection; and conducted on 6 subjects, it was done to estimate the time required for filling out the sheets and also to check the clarity, applicability, relevance of the questions. Based on the results of the pilot study, the necessary modifications were carried out.

\subsection{Ethical Considerations}

A necessary approval from Oncology hospital authority was taken after issuing an official letter from the dean of Faculty of Nursing, Menoufia University. An informed consent to participate in the current study was taken after the purpose of the study was clearly explained to each woman. Confidentiality of obtained personal data, as well as respect of participants' privacy was totally ensured. A summary of the intervention was explained to each woman before volunteering to participate in the study and women were informed that they can withdraw from the study at any time. No invasive procedure was required.

\subsection{Field Work}

Interview and data collection: women attend the outpatient oncology hospital to receive the prescribed treatment for breast cancer, and whom fulfilled inclusion criteria are recruited by the researchers to collect data after informed consent were obtained. According to the collected data and diagnosis of oncologist, breast cancer women with sexual problems were identified.

The researchers explained the aim of the study, scheduled times and frequency of counseling sessions to all selected women to assure adherence to selected interventions.

The intervention included "The Application of PLISSIT Counseling Model for sexual therapy.

An evaluation phase: post intervention data were collected at the end of the study period (three weeks) at out-patient of Oncology Institute, Menoufia University. All three scales (body image scale, female sexual function index (FSDI), the revised dyadic adjustment scale) was measured after application of PLISSIT Counseling Model intervention.

\section{Components of PLISSIT Counseling Model Sexual Intervention}

\subsection{Description of Counseling Sessions}

The counseling sessions was conducted in oncology 
outpatient clinic at oncology Institute, Menoufia university hospital.

The participated women received the counseling session individually.

The researchers established the session's environment to be comfortable and quiet.

The researchers used a well prepared intervention materials and contents in the form of comprehensive illustrated booklet i.e. (pictorial form) and educational videos related to the selected nursing management of breast cancer.

A six counseling sessions each session lasting 2 hrs for three weeks according to Nami Chun, (2011) ${ }^{[14]}$ was achieved.

I. Permission: The researchers talk about cancer and sexuality with patients. Women of breast cancer provided a permission to think and talk about the sexual issues, sexual feelings/relationships and normalize this concern in a safe and comfortable environment. At this step, the researchers asked an open -ended and general question such as: what has your experience been with sexual issues since your diagnosis of cancer.

II. Limited Information: The researchers offered a brief information to the patient about the effect of cancer and related treatments on sexual function. In this stage, the researchers focused on addressing and correcting myths e.g. (I can spread cancer through intercourse).

III. Specific suggestion: The researchers used a problem solving approach in addressing patient's issues that experienced personally.

For example if a women expressed anticipatory anxiety about bad body image after mastectomy. The researchers addressed available compensatory artificial -made-breast lining/s that is healthy in use without any allergic reactions (under doctor supervision).

Another example if a women expresses anticipatory anxiety about sexual intercourse with her husband for fear of pain or discomfort, the researchers addressed relaxation strategies, appropriate medications (under doctor prescription).

Through this phase the researchers provided nursing related interventions to manage side effects of treatment as side effects of treatment have great impact on sexual activities.

\subsection{Nursing Intervention}

- Education: understanding breast cancer treatment, and its side effects.

- Physical activity including walking for at least 30 minutes / day. Also, performing shoulders range of motion exercise.

- Relaxation techniques including breathing exercise, distraction and recreation.

- Diet therapy (high fiber diet, low fat diet, high vegetables/fruits diet)

- Managing body image by wearing attractive clothes, reconstruction of breast makeup, special lingerie, perfumes

- Management of lymphedema: including rang of motion, bandage, arm up, prevent infection.

- Psychological counseling and support.

- Nursing management for nausea, vomiting, diarrhea, dyspnea, gingivitis,

VI: Intensive therapy: Identify any difficulties (for example: financial difficulties)
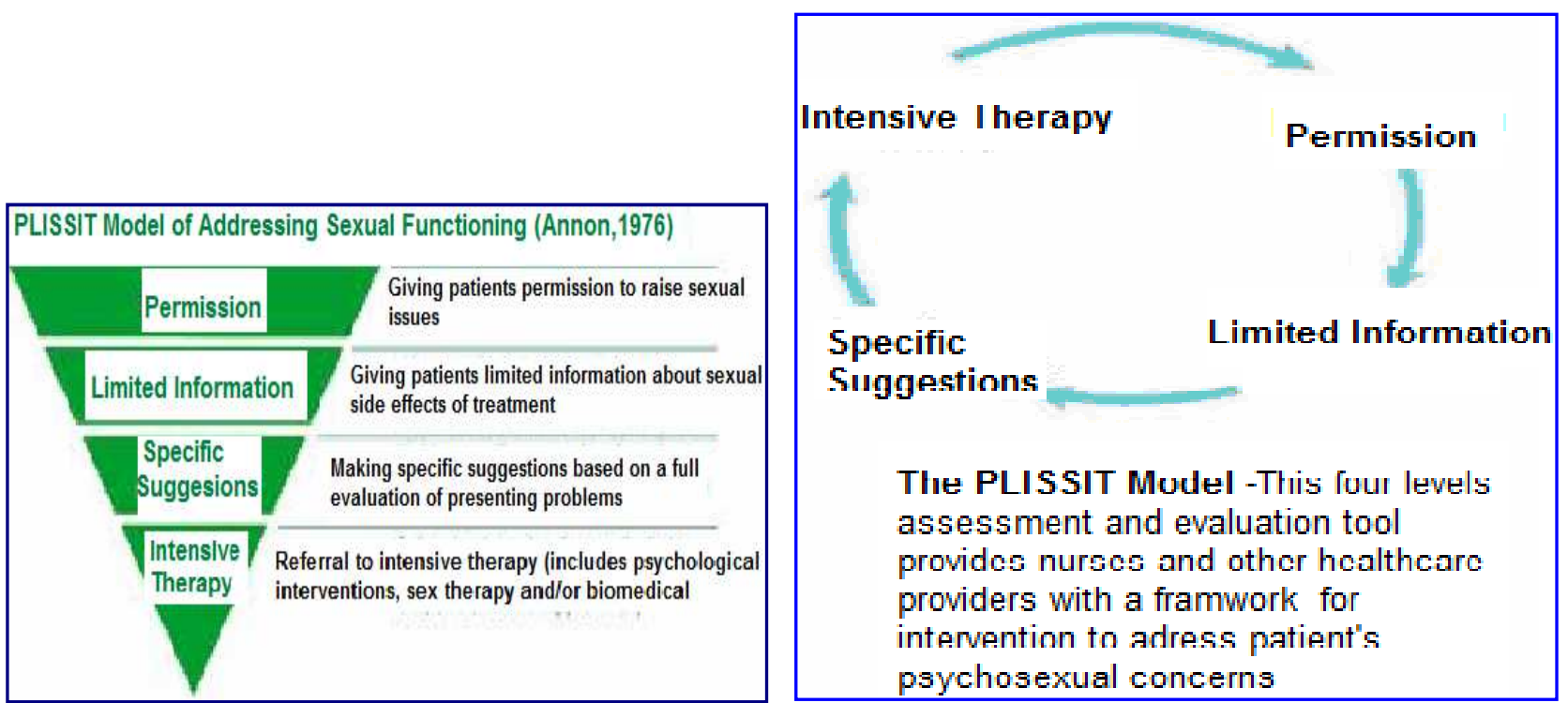

Figure (1),(2). PLISSIT Counseling Model of Addressing Sexual Functioning

Jack, S., Annon, (1976). The PLISSIT model: A proposed conceptual scheme for the behavioral treatment of sexual problems. Journal of Sex Education and Therapy, 2(2), 1-15. 
In this stage, the researchers identified services to which women can be referred for more intensive or comprehensive treatment (social worker, sex therapist, psychological, medical specialist)

\subsection{Statistical Analysis}

The collected data were organized, tabulated and statistically analyzed using SPSS software, version 16. For quantitative data, the range, mean and standard deviation were calculated. For qualitative data, comparison between two groups and more was done using Chi-square test $\left(\chi^{2}\right)$. For comparison between means of two groups of nonparametric analysis ( $Z$ value of Mann-Whitney $U$ test) were used. For comparison between means of two related groups ( pre \& post data) of parametric data, paired t-test was used. For comparison between means of two related groups ( pre \& post intervention) of non-parametric data, $Z$ value of Wilcoxon Signed Ranks Test was used. For comparison between more than two means of non-parametric data, Kruskal-Wallis $\left(\mathrm{X}^{2}\right)$ was calculated. Significance was adopted at $p<0.05$ for interpretation of results of tests of significance. ${ }^{[15]}$

\subsection{Limitation of the Study}

Some participated women withdrawn from the study after filling the interview questionnaire, either they considered the sexual issues are prohibited to be discussed openly (culture issue), or due to social difficulties (time and responsibilities...).

\section{Results}

Table 1. Displayed demographic, menstrual and medical data of studied women with breast cancer. The table showed that, the mean age of women with breast cancer was $43.11 \pm 10.02$ and the higher percent of diseased women were had $30-<40$ years. Regarding education, more than half of sample $(56.1 \%)$ had secondary level of education. Regarding menstrual history, $25.8 \%$ of total studied sample were menopauses, mean while, $57.2 \%$ of women had secondary amenorrhea- related -chemotherapy.

Regarding medical data, it showed that, more than half of sample $(56.1 \%)$ was detected breast cancer by breast selfexamination. About $43.9 \%$ and $37.9 \%$ were in cancer stage II, III respectively. Regarding type of treatment $37.9 \%$ of all studied sample were treated with surgery combined with chemotherapy and radiotherapy. The same table also showed that most of studied sample $(95.5 \%)$ underwent breast tumor removal and $85.7 \%$ were had a radical mastectomy .Only, $14.3 \%$ had excised breast tumor only. Also, most of the studied sample $(83.3 \%)$ received chemotherapy.
Table 1. Demographic, menstrual and medical data of studied women with breast cancer $(n=66)$.

\begin{tabular}{|c|c|c|}
\hline \multirow{2}{*}{$\begin{array}{l}\text { Demographic,Menstrual \& Medical data } \\
\text { I: Demographic data }\end{array}$} & \multicolumn{2}{|c|}{$\begin{array}{l}\text { The studied women with } \\
\text { breast cancer }(n=66)\end{array}$} \\
\hline & $\mathrm{N}$ & $\%$ \\
\hline \multicolumn{3}{|l|}{-Age (years): } \\
\hline $30-<40$ & 34 & 51.5 \\
\hline $40-<50$ & 19 & 28.8 \\
\hline $50-<60$ & 4 & 6.1 \\
\hline $60-63$ & 9 & 13.6 \\
\hline Range & \multicolumn{2}{|c|}{$30-63$} \\
\hline Mean \pm SD & \multicolumn{2}{|c|}{$43.11 \pm 10.02$} \\
\hline \multicolumn{3}{|l|}{-Education level: } \\
\hline Illiterate & 15 & 22.7 \\
\hline Primary & 4 & 6.1 \\
\hline Secondary & 37 & 56.1 \\
\hline University & 10 & 15.2 \\
\hline \multicolumn{3}{|l|}{ II: Menstrual history } \\
\hline \multicolumn{3}{|l|}{-Menopause: } \\
\hline Yes & 17 & 25.8 \\
\hline No & 49 & 74.2 \\
\hline \multicolumn{3}{|l|}{-Secondary amenorrhea: } \\
\hline No & 21 & 42.8 \\
\hline Yes & 28 & 57.2 \\
\hline \multicolumn{3}{|l|}{-If yes, cause: } \\
\hline Chemotherapy & 28 & 100 \\
\hline \multicolumn{3}{|l|}{-How breast cancer was detected: } \\
\hline By doctor & 29 & 43.9 \\
\hline By breast self-examination & 37 & 56.1 \\
\hline \multicolumn{3}{|l|}{-Stages of breast cancer: } \\
\hline Stage I & 12 & 18.2 \\
\hline Stage II & 29 & 43.9 \\
\hline Stage III & 25 & 37.9 \\
\hline \multicolumn{3}{|l|}{-Type of treatment regimen : } \\
\hline Surgery & 9 & 13.6 \\
\hline Chemotherapy & 3 & 4.5 \\
\hline Surgery + Chemotherapy & 25 & 37.9 \\
\hline Surgery + Chemotherapy. + Radiotherapy & 25 & 37.9 \\
\hline Surgery+ Radiotherapy & 2 & 3.0 \\
\hline All & 2 & 3.0 \\
\hline \multicolumn{3}{|l|}{-Breast cancer removal: } \\
\hline Yes & 63 & 95.5 \\
\hline No & 3 & 4.5 \\
\hline \multicolumn{3}{|l|}{-If yes, type of surgery performed: } \\
\hline Breast tumour excision only & 9 & 14.3 \\
\hline Radical mastectomy (breast \& lymph nodes) & 54 & 85.7 \\
\hline \multicolumn{3}{|l|}{ Women undergone Chemotherapy: } \\
\hline Yes & 55 & 83.3 \\
\hline No & 11 & 16.7 \\
\hline
\end{tabular}


Table 2. Treatment side effects pre and post PLISSIT counseling model among studied women with breast cancer ( $n=66)$.

\begin{tabular}{|c|c|c|c|c|c|c|c|}
\hline \multirow{3}{*}{ Side effects of breast cancer treatment } & \multicolumn{4}{|c|}{$\begin{array}{l}\text { The studied women with breast cancer pre and } \\
\text { post PLISSIT intervention }(n=66)\end{array}$} & \multirow{3}{*}{$\%$ of improvement } & \multirow{3}{*}{$\chi^{2}$} & \multirow{3}{*}{$\mathbf{P}$} \\
\hline & \multicolumn{2}{|c|}{ Pre } & \multicolumn{2}{|c|}{ Post } & & & \\
\hline & $\mathbf{N}$ & $\%$ & $\mathbf{n}$ & $\%$ & & & \\
\hline \multicolumn{8}{|l|}{ treatment side effects: } \\
\hline Nausea \& vomiting & 32 & 48.5 & 16 & 24.2 & $24.3 \%$ & 8.32 & $0.004 *$ \\
\hline Diarrhea & 27 & 40.9 & 13 & 19.7 & $21.2 \%$ & 6.64 & $0.010^{*}$ \\
\hline Loss of hair & 42 & 63.6 & 34 & 51.5 & $12.1 \%$ & 2.09 & 0.149 \\
\hline Gingivitis & 37 & 56.1 & 26 & 39.4 & $16.7 \%$ & 3.71 & 0.054 \\
\hline Loss of appetite & 28 & 42.4 & 17 & 25.8 & $16.6 \%$ & 3.76 & 0.052 \\
\hline Loss of body weight & 28 & 42.4 & 17 & 25.8 & $16.6 \%$ & 3.76 & 0.052 \\
\hline Anaemia & 30 & 45.5 & 23 & 34.8 & $10.7 \%$ & 1.31 & 0.252 \\
\hline Dyspnea & 30 & 45.5 & 22 & 33.3 & $12.2 \%$ & 1.79 & 0.181 \\
\hline Pain & 44 & 66.7 & 29 & 43.9 & $22.8 \%$ & 7.98 & $0.005^{*}$ \\
\hline Arm swelling & 37 & 56.1 & 29 & 43.9 & $12.2 \%$ & 1.86 & 0.173 \\
\hline
\end{tabular}

*Significant $(\mathrm{P}<0.05)$

Table 2. Presented treatment's side effects variation pre and post intervention. The table displayed an improvement in all side effects after application of PLISSIT model. A significant relationship was found between treatment side effect pre and post intervention regarding nausea $\&$ vomiting, diarrhea and pain $(\mathrm{P}<0.05)$.

Table 3. Body image scores pre and post PLISSIT counseling sexual model among studied women with breast cancer ( $n=66)$.

\begin{tabular}{|c|c|c|c|c|c|c|}
\hline \multirow{3}{*}{$\begin{array}{l}\text { Body image Scale } \\
\text { Scores }\end{array}$} & \multicolumn{4}{|c|}{$\begin{array}{l}\text { The studied women with breast cancer pre and post } \\
\text { PLISSIT }(n=66)\end{array}$} & \multirow[t]{3}{*}{$\chi^{2}$} & \multirow[t]{3}{*}{$\mathbf{P}$} \\
\hline & \multicolumn{2}{|c|}{ Pre } & \multicolumn{2}{|c|}{ Post } & & \\
\hline & $\mathrm{N}$ & $\%$ & $\mathrm{~N}$ & $\%$ & & \\
\hline \multicolumn{7}{|c|}{ Body image scale level: } \\
\hline Good & 24 & 36.4 & 36 & 54.5 & 8.403 & $0.015^{*}$ \\
\hline Considerable & 10 & 15.2 & 14 & 21.2 & & \\
\hline Bad & 32 & 48.5 & 16 & 24.2 & & \\
\hline \multicolumn{7}{|c|}{ Body image scale scores: } \\
\hline Range (9-36) & \multicolumn{2}{|c|}{$9-36$} & \multicolumn{2}{|l|}{$9-36$} & & \\
\hline Mean \pm SD & \multicolumn{2}{|c|}{$24.85 \pm 9.83$} & \multicolumn{2}{|c|}{$19.78 \pm 8.51$} & & \\
\hline Paired t-test & \multicolumn{2}{|c|}{3.768} & & & & \\
\hline $\mathrm{P}$ & \multicolumn{2}{|c|}{$0.001 *$} & & & & \\
\hline \multicolumn{7}{|c|}{$\%$ of improvement of body image scores: } \\
\hline Range & \multicolumn{4}{|c|}{$75-140 \%$} & & \\
\hline Mean \pm SD & \multicolumn{4}{|c|}{$66.70 \% \pm 18.94$} & & \\
\hline
\end{tabular}

*Significant $(\mathrm{P}<0.05)$

Table 3. Represented body image scores pre and post intervention among the studied women with breast cancer. It showed statistically significant difference between body image scale level before and after application of PLISSIT counseling model. The higher percent of body image level were bad (48.5\%) pre intervention; it improved to become good $(54.5 \%)$ post intervention. The mean score of body image were $19.78 \pm 8.51$ after application of PLISSIT counseling model compared to $24.85 \pm 9.83$ before these interventions. The range of body image scores improvement was $75-140 \%$ after intervention. 
Table 4. Couple satisfaction pre and post PLISSIT counseling model intervention among studied women with breast cancer ( $n=66)$.

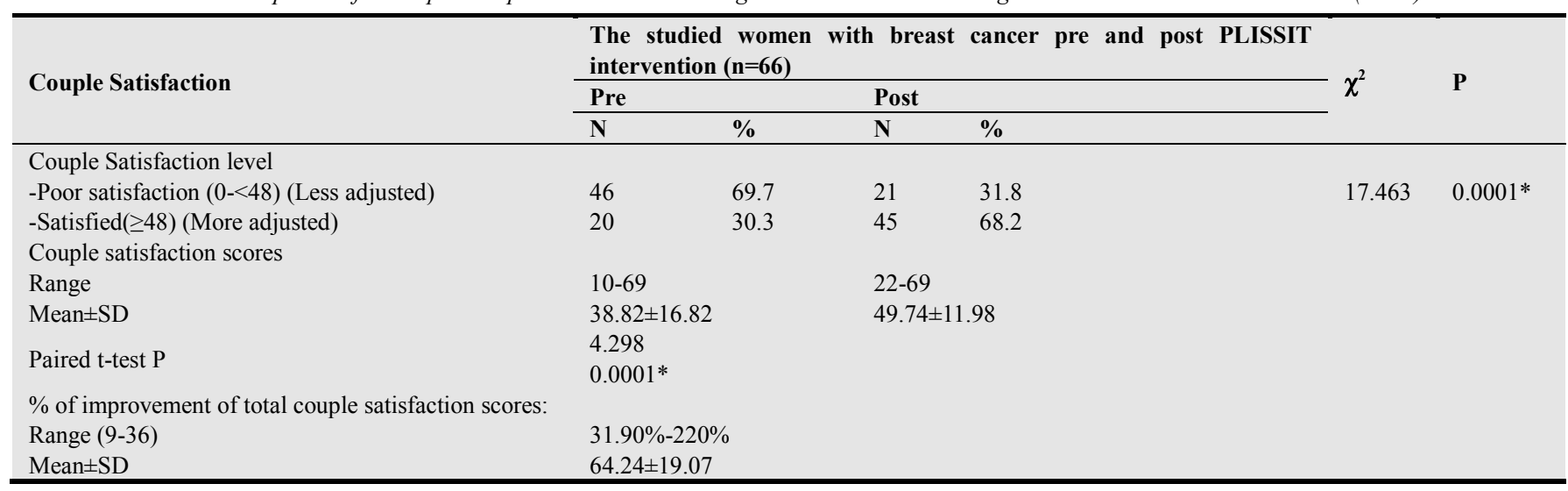

*Significant $(\mathrm{P}<0.05)$

Table 4. Displayed couple satisfaction pre and post application of PLISSIT counseling model among studied women. It showed a statistically significant differences in couple satisfaction before and after application of PLISSIT model $(\mathrm{P}<0.0001)$. The range of improvement of total couple satisfaction scores after application of PLISST counseling model was $31.90 \%-220.0 \%$.

Table 5. Female Sexual Function Index (FSFI) main domains pre and post PLISSIT counseling model intervention among studied women with breast cancer $(n=66)$.

\begin{tabular}{|c|c|c|c|c|c|}
\hline \multirow{3}{*}{$\begin{array}{l}\text { Female Sexual } \\
\text { (FSFI) }\end{array}$} & \multirow[t]{3}{*}{ Function Index } & \multicolumn{2}{|c|}{$\begin{array}{l}\text { Mean scores of FSFI main domains of studied women with breast cancer pre and } \\
\text { post PLISSIT intervention }(n=66)\end{array}$} & \multirow{3}{*}{$Z$ value } & \multirow{3}{*}{$\mathbf{P}$} \\
\hline & & Pre & Post & & \\
\hline & & Range Mean \pm SD & Range Mean \pm SD & & \\
\hline \multicolumn{6}{|c|}{ FSFI main domains scores: } \\
\hline Desire & $(1.2-6)$ & $\begin{array}{l}0-4.80 \\
1.45 \pm 1.55\end{array}$ & $\begin{array}{l}0-4.80 \\
2.19 \pm 1.51\end{array}$ & 1.623 & 0.108 \\
\hline Arousal & $(0-6)$ & $\begin{array}{l}0-4.80 \\
1.55 \pm 1.59\end{array}$ & $\begin{array}{l}0-4.80 \\
2.27 \pm 1.52\end{array}$ & 2.665 & $0.009 *$ \\
\hline Lubrication & $(0-6)$ & $\begin{array}{l}0-5.40 \\
1.99 \pm 2.16\end{array}$ & $\begin{array}{l}0-5.40 \\
2.94 \pm 2.14\end{array}$ & 2.547 & $0.012 *$ \\
\hline Orgasm & $(0-6)$ & $\begin{array}{l}0-5.60 \\
1.96 \pm 2.05\end{array}$ & $\begin{array}{l}0-6 \\
3.04 \pm 2.24\end{array}$ & 2.884 & $0.005^{*}$ \\
\hline Satisfaction & $(0-6)$ & $\begin{array}{l}0-6 \\
1.89 \pm 1.95\end{array}$ & $\begin{array}{l}0-6 \\
3.01 \pm 2.22\end{array}$ & 3.059 & $0.003 *$ \\
\hline Pain & $(0-6)$ & $\begin{array}{l}0-6 \\
2.27 \pm 2.16\end{array}$ & $\begin{array}{l}0-6 \\
3.37 \pm 2.12\end{array}$ & 2.962 & $0.004 *$ \\
\hline
\end{tabular}

*Significant $(\mathrm{P}<0.05) \mathrm{Z}$ value of Wilcoxon Signed Ranks Test

Table 5. Showed Female Sexual Function Index (FSFI) main domains pre and post PLISSIT model application among the studied women. It showed a statistically significant differences in all domains (arousal, lubrication, orgasm, satisfaction, and pain) of FSFI $(\mathrm{p}<.05)$ except with sexual desire, it is insignificant.

Table 6. Total Female Sexual Function Index (FSFI) pre and post PLISSIT counseling model among studied women with breast cancer (n=66).

\begin{tabular}{|c|c|c|c|c|c|c|}
\hline \multirow{3}{*}{ Female Sexual Function Index (FSFI) } & \multicolumn{4}{|c|}{ The studied women with breast cancer pre and post PLISSIT $(n=66)$} & \multirow{3}{*}{$\chi^{2}$} & \multirow{3}{*}{$\mathbf{P}$} \\
\hline & \multicolumn{2}{|c|}{ Pre } & \multicolumn{2}{|c|}{ Post } & & \\
\hline & $\mathbf{N}$ & $\%$ & $\mathbf{N}$ & $\%$ & & \\
\hline \multicolumn{7}{|l|}{ Sexual functioning: } \\
\hline -Sexual dysfunction $(<26.55)$ & 31 & 47.0 & 26 & 39.4 & 7.399 & $0.025 *$ \\
\hline -Sexually functioning $(\geq 26.55)$ & 6 & 9.1 & 18 & 27.3 & & \\
\hline -Not sexually active in the last 4 weeks & 29 & 43.9 & 22 & 33.3 & & \\
\hline \multicolumn{7}{|l|}{ Total FSFI scores $(1.2-36)$ : } \\
\hline Mean \pm SD & \multicolumn{2}{|c|}{$11.12 \pm 11.06$} & \multicolumn{2}{|c|}{$16.83 \pm 11.27$} & & \\
\hline$Z$ value & \multicolumn{4}{|c|}{4.626} & & \\
\hline $\mathrm{P}$ & \multicolumn{4}{|c|}{$0.0001 *$} & & \\
\hline \multicolumn{7}{|c|}{$\%$ of improvement of total FSFI scores post PLISST: } \\
\hline Range & \multicolumn{6}{|c|}{$19.20 \%-186.54 \%$} \\
\hline Mean \pm SD & \multicolumn{6}{|c|}{$58.06 \% \pm 25.68$} \\
\hline
\end{tabular}

*Significant $(\mathrm{P}<0.05) \mathrm{Z}$ value of Wilcoxon Signed Ranks Test 
Table 6. Displayed total Female Sexual Function Index (FSFI) pre and post intervention among studied women. It showed a statistically significant difference in total FSFI before and after application of intervention $(p<0.05)$. The range of improvement of total FSFI scores post intervention was $19.20 \%-186.54 \%$.

Table 7. Relationship between couple satisfaction and both body image and sexual functioning post PLISSIT intervention among the study women with breast cancer $(n=66)$.

\begin{tabular}{|c|c|c|c|c|c|c|c|c|c|c|c|c|c|}
\hline \multirow{4}{*}{$\begin{array}{l}\text { Couple } \\
\text { Satisfaction }\end{array}$} & \multicolumn{13}{|c|}{ Female sexual functioning (FSF) of the study women with breast cancer pre and post PLISSIT Intervention (n=66) } \\
\hline & \multicolumn{6}{|c|}{ Pre } & \multicolumn{7}{|c|}{ Post } \\
\hline & \multirow{2}{*}{$\begin{array}{l}\text { Sexual } \\
\text { dysfunction } \\
(\mathrm{n}=31) \\
\mathrm{N}\end{array}$} & \multicolumn{3}{|c|}{$\begin{array}{l}\text { Sexually functioning } \\
(n=6)\end{array}$} & \multicolumn{2}{|c|}{$\begin{array}{l}\text { No sexual practice } \\
(n=29)\end{array}$} & \multicolumn{3}{|c|}{$\begin{array}{l}\text { Sexual dysfunction } \\
(n=26)\end{array}$} & \multicolumn{2}{|c|}{$\begin{array}{l}\text { Sexually functioning } \\
(n=18)\end{array}$} & \multirow{2}{*}{$\begin{array}{l}\text { No sexual practice } \\
(n=22)\end{array}$} & \multirow[t]{2}{*}{$\begin{array}{l}\chi^{2} \\
\mathbf{P}\end{array}$} \\
\hline & & $\%$ & $\mathbf{N}$ & $\%$ & $\mathbf{N}$ & $\%$ & $\mathbf{n}$ & $\%$ & $\mathbf{n}$ & $\%$ & $\mathbf{n}$ & & \\
\hline \multicolumn{14}{|l|}{$\bullet$ Couple } \\
\hline Satisfied & 11 & 55.0 & 2 & 10.0 & 7 & 35.0 & 16 & 44.4 & 17 & 28.9 & 12 & 26.7 & $0.0002 *$ \\
\hline$\chi^{2} \mathrm{P}$ & $\begin{array}{l}0.946 \\
0.624\end{array}$ & & & & & $\begin{array}{l}8.143 \\
0.017^{*}\end{array}$ & & & & & & & \\
\hline \multicolumn{14}{|l|}{$\begin{array}{l}\text {-Body Image } \\
\text { scale }\end{array}$} \\
\hline Good(9-17) & 4 & 12.9 & 4 & 66.7 & 16 & 55.2 & 3 & 11.5 & 17 & 94.4 & 16 & 72.7 & 61.762 \\
\hline $\begin{array}{l}\text { Considerable } \\
(18-26)\end{array}$ & 1 & 3.2 & 2 & 33.3 & 7 & 24.1 & 8 & 30.8 & 1 & 5.6 & 5 & 22.7 & $0.0001 *$ \\
\hline $\operatorname{Bad}(27-36)$ & 26 & 83.9 & 0 & 0 & 6 & 20.7 & 15 & 57.7 & 0 & 0 & 1 & 4.5 & \\
\hline$\chi^{2} \mathrm{P}$ & $\begin{array}{l}30.329 \\
0.0001 *\end{array}$ & & & & & & & & & & & & \\
\hline
\end{tabular}

*Significant $(\mathrm{P}<0.05)$

Table 7. Presented relationship between couple satisfaction and both body image and sexual functioning post PLISSIT intervention among studied women. It showed that, there was a significant relationship between couple satisfaction and both body image and sexual functioning as a sexuality predictors $(p<0.05)$. The same table showed statistically significant difference and improvement of couple satisfaction and body image scale in relation to sexual functioning after application of PLISSIT counseling model than before intervention.

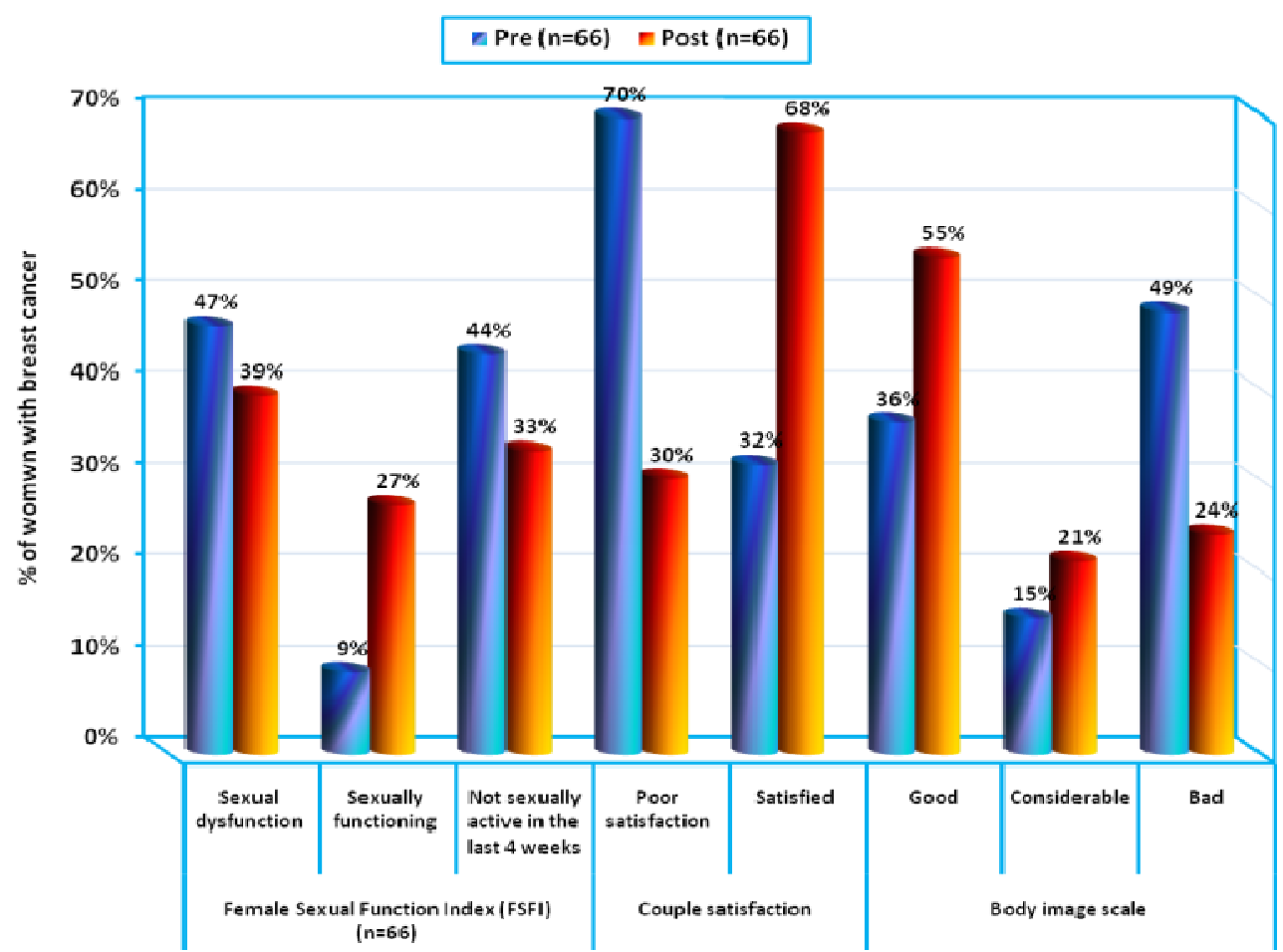

Figure (3). Levels of body image scores, couple satisfaction and total Female Sexual Function Index (FSFI) pre and post PLISSIT counseling intervention among the studied women with breast cancer $(n=66)$. 
Figure 3. Displayed levels of body image scores, couple satisfaction and total female sexual function index (FSFI) pre and post PLISSIT model application among studied women with breast cancer. It showed that, $27 \%$ of women become well sexually functioning after application of counseling model compared to $9 \%$ of women before its application. Regarding couple satisfaction it showed that, $68 \%$ of women had a satisfied couple relation after counseling model application compared to $32 \%$ of women before application. The Same figure also showed an improvement in percentage of women who had bad body image $24 \%$ after model application compared to $49 \%$ of them before its application. i.e. Lower scores indicating greater level of body image.

Figure 4. This figure showed an improvement among studied women with breast cancer for mean scores of couple satisfaction, total Female Sexual Function Index (FSFI) and body image after application of counseling model. They improved to become 49.7, 16.8 and 19.7, respectively compared to $38.8,11.1$ and 24.8 respectively before model application.

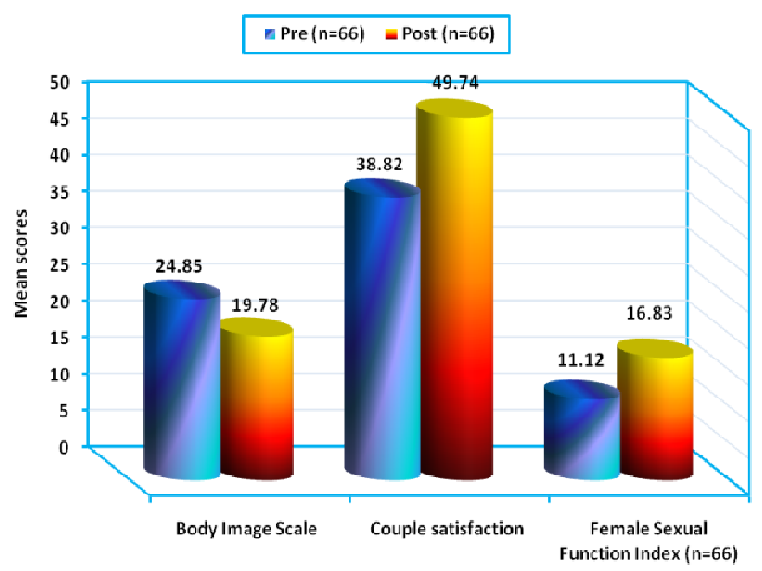

Figure 4. Mean scores of body image scale, couple satisfaction and total Female Sexual Function Index (FSFI) pre and post PLISSIT counseling model among studied women with breast cancer $(n=66)$.

\section{Discussion}

Sexual health concerns are distressing complications for patients and their husbands during the diagnostic, treatment, and recovery phases of their cancer. Healthy sexual functioning is a vital step toward reestablishing their sense of normalcy and well-being. ${ }^{[16]}$ Sexual dysfunction is a common and under recognized disorder in women with breast cancer. It may be related to multiple factors: physical decline due to treatment, psychological distress due to diagnosis, change in hormonal milieu and/or poor body image. ${ }^{[17]}$

The current study showed that the highest percent $(51.5 \%)$ of diseased women were younger $(30-<40)$ years with mean age $43.11 \pm 10.02$. the present study findings was matched with Abd El-Aziz, Mersal \& Taha (2011) ${ }^{[18]}$ who found that the mean age of studied women in their study was $43.2 \pm 6.3$ years. Also, the present study showed that age of women ranged from 30-63 years the current study findings is congruent with Gauri et al., (2014) ${ }^{[17]}$ who studied the impact of breast cancer diagnosis and treatment on sexual dysfunction and reported that the age of women in their study was ranged between 33-73 years. Mean while, Rapiti et al., (2005) ${ }^{[19]}$ found no effect of age on diagnosis or/and survival of breast cancer women.

The current study findings indicated that, more than half of studied women had intermediate level of education.This result was consistent with a study conducted by Abd El-Aziz et al., (2011) ${ }^{[18]}$ who reported that, more than half of studied women had secondary level of education (56.7\%).on the same line, Nicoletta, Giulia, Elisa, Paola \& Riccardo (2010) ${ }^{[20]}$ found that, population in their study had an average level of education. This may be attributed to low cognitive abilities and increased health illiteracy related to leading causes for breast cancer.

Some studies declared the health hazards of breast cancer related- treatment on women 's sexuality and body image,explaining that some determinants are responsible for the appearance of side effects related sexuality on women undergoing treatment.The present study indicated that breast cancer determinants were stage of cancer as the majority of studied women with breast cancer were in stage II and III, type of treatment as majority of women treated with chemotherapy combined with surgery and chemotherapy, type of surgery, side effect of chemotherapy as it is considered important determinants for the occurrence of these hazards. These findings was consistent with study conducted by Graziottin (2005) ${ }^{[21]}$ who studied breast cancer and its effect on influencing body image and sexuality and reported that determinants of breast cancer were stage of cancer, type of breast surgery and hair loss.

\subsection{Cancer Breast Treatment}

The present study indicated that chemotherapy affects women sexuality, as more than half of studied sample used chemotherapy as type of treatment combined with surgery and radio therapy. This result of was in line with Arora et al., (2001) [22] who studied the impact of surgery and chemotherapy on the quality of life of younger women with breast carcinoma and stated that chemotherapy had a negative impact on women's sexual functioning $(\mathrm{P}=0.01)$ and their physical well-being $(\mathrm{P}=0.09)$. Likewise, Bakwell \& Volker (2005) ${ }^{[23]}$ showed that all types of treatment for breast cancer had a significant impact on body image and menopausal status and finally results in sexual problems. On the other hand, Shiahna, (2008) ${ }^{[24]}$ found that, breast cancer treatment such as chemotherapy and surgical treatment did not disrupt sexual functioning.

The majority of women undergone breast cancer surgery ; $85.7 \%$ were had a radical mastectomy.Only, $14.3 \%$ had excised breast tumor.This result was in line with Sbitti, (2010) ${ }^{[25]}$ who studied breast cancer treatment and sexual dysfunction among Moroccan's women.They reported that 
most of women had undergone breast surgery (radical mastectomy $66.5 \%$, lumpectomy $33.5 \%$ ).

\subsection{Side Effects- Related- Treatment}

Cancer therapies have the potential to affect sexuality directly by gonadal and hormonal effects and indirectly by causing fatigue, apathy, nausea, vomiting, and malaise. Sleep and appetite disturbances can interfere with libido. ${ }^{[26]}$ Globally, chemotherapy is a major determinant of sexual dysfunction, affecting all the phases of the sexual response cycle. This repercussion is particularly stern and catastrophic for young women. ${ }^{[27]}$

Regarding side effects of chemotherapy, the most common side effects were nausea \& vomiting, diarrhea and pain before application of PLISST model. This result is consistent with Fobair, Stewart \& Chang (2006) ${ }^{[28]}$ who studied body image and sexual problems in young women with breast cancer and stated that chemotherapy, causes alopecia, nausea, vomiting, nails changes and weight gain or loss. On the same line, National breast cancer center (2004) ${ }^{[29]}$ reported that chemotherapy side effects were feelings of fatigue, apathy, nausea, vomiting and malaise and sleep or appetite disturbances and these effects interfere with libido. An improvement in all side effects after application of PLISST counseling model was appeared. With suggestions provided by the researchers during application the model, a problem solving approach is useful to address an issue that the patient has experienced personally and manage sexuality problem and side effects of treatment.

\subsection{Women's Undergoing Treatment and Their Sexual Dysfunction}

The current study demonstrated that, breast cancer affect many aspects of women's sexuality prior the commencement of intervention (application of PLISSIT counseling model). Also, it showed an improvement in all sexual function index domains (arousal, lubrication, orgasm, satisfaction, and pain) post intervention except with sexual desire. This was in line with Knapstein et al., (2002) ${ }^{[30]}$ who found that, mastectomy resulted in lower sexual desire. The most numerous dysfunctions are those which originate easily from compromises in psychological nature while the lowest dysfunctions were of physical nature ( lubrication and pain).

\subsection{Women's Undergoing Treatment and Their Body Image}

The term "body image" describes someone's overall wholeness, functionality, and ability to relate to others. Body image is part of each person's self-worth. ${ }^{[31]}$ The present study findings showed that nearly half of study sample (48.5\%) had bad body image level. This result was consistent with Rogers, and Kristjanson (2002) ${ }^{[32]}$ who ascertain that, numerous studies have identified a greater frequency of body image alterations after mastectomy. These findings were also consistent with Jody Pelusi (2006) ${ }^{[33]}$ who stated that, altered body image seems to be more pronounced if chemotherapy or hormonal therapy is added to the treatment regimen. Likewise, Knapstein et al., (2002) ${ }^{[30]}$ found that, mastectomy resulted in changes in body image. On the other hand, Shiahna (2008) ${ }^{[24]}$ found that, body image was not influenced by what type of surgical treatment a woman underwent but rather her mood impacted how she felt about her own body as well as how she perceived her partner felt about her body.

\subsection{Women's Undergoing Treatment and Their Couple Satisfaction}

The current study findings showed that, the majority of studied cancer women $(69.7 \%)$ had poor couple satisfaction. This result was congruent with Speer, Hillenberg, Sugrue (2005) ${ }^{[34]}$ who studied sexual functioning determinants in breast cancer survivors and stated that, the dynamics of relationships can be strained and changed with a cancer diagnosis and therapy. The survivors' level of relationship distress, depression and age may be seen as the most significant variables affecting arousal, orgasm, lubrication, satisfaction and sexual pain rather than hormonal levels.

\subsection{Relationship between Sexual Functioning, Body Image and Couple Satisfaction}

The present study indicated that, altered body image had an effect on sexuality and couple satisfaction. This study findings was matching with studies conducted by Michael,(2000) ${ }^{[35]}$ and Ganz (2002) ${ }^{[36]}$ whom reported that a growing body of evidence suggests that changes in body image after breast cancer and its treatment may have direct effects on sexuality, sexual response, sexual roles, and relationships. The alterations in body image occur when there is a discrepancy between the ways someone formerly perceived herself and how she now sees herself as a result of cancer and its treatment.

\subsection{Application of PLISSIT Counseling Model on Breast Cancer}

One of the most widely accepted screening sexual models that could be useful in oncology is the PLISSIT model created by Annon,(1976) ${ }^{[37]}$ : Permission (to discuss the subject), Limited Information (not to overwhelm the patient), Specific Suggestions (to-the-point pragmatic information) and Intensive Therapy (in the case of expert referral needed). ${ }^{[38]}$. The present study showed an improvement of sexual functioning, body image, couple satisfaction after application of PLISST model. On the same line with study conducted by Nami Chun, (2011) ${ }^{[14]}$, who studied effectiveness of PLISSIT Model Program on Female Sexual Function for women with Gynecologic Cancer reported that the results indicated that the three-weeks PLISSIT model sexual program was effective in increasing sexual function for women with gynecologic cancer. Nurses may contribute to improving women's sexual function by utilizing the PLISSIT counseling model. Application of PLISSIT include Informational rehabilitation: understanding breast cancer treatment, side effects of treatment, physical 
activity, diet therapy, managing body image by wearing attractive clothes, makeup, special lingerie, perfumes, symptom nursing management for nausea, vomiting, diarrhea, dyspnea, gingivitis.

\subsection{Informational Rehabilitation}

Informational rehabilitation given to breast cancer patients is important for the adjustment to this chronic condition. Rees and Bath (2000) ${ }^{[39]}$ concluded that, women with breast cancer have distinct needs for information throughout their breast cancer journeys, indicating that information needs change with time after diagnosis and with treatment-related events. Engel et al. (2003) ${ }^{[40]}$ insisted that information interventions to improve quality of life are required for treatment decisions. Once patients have knowledge of the disease, they cope better with their condition. Therefore, appropriate education is important to a patient's quick recovery and rehabilitation. The current study supplied the participated women with breast cancer with an informational rehabilitation that included education about types of treatment, diet therapy, reconstruction of the breast, side effects of treatment, and symptoms management for pain and discomfort.

Education about sexual anatomy, sexual responsively and the natural changes a couple experiences with time may also be very helpful for the couple who is struggling with a change in their sexual and intimate lives. Sexual health resources to enhance body image by (wigs, special lingerie, attachable nipples etc) should be widely available to help the cancer patient /survivor reclaim her sexual self-esteem. ${ }^{[41]}$

\subsection{Physical Activity and Walking}

Stevinson and Fox (2005) ${ }^{[42]}$ suggested that, effects of physical activity and rehabilitation led to improved fitness, reduced fatigue, enjoyment, enhanced mood and a sense of achievement in breast cancer patients. According to this study, physical activity rehabilitation included walking and recovery of shoulder range of movement. Likewise, Campbell, Mutrie, White, McGuire, and Kearney (2005) ${ }^{[43]}$ emphasized the importance of exercise of breast cancer patients and reported using exercise(shoulder range movements and walking) as an adjunctive rehabilitation therapy for women with early stage breast cancer and receiving chemotherapy/ radiotherapy to reduce fatigue and improve physical functioning and quality of life.

\subsection{Relaxation Technique}

According to current study, the researchers teach and encourage the participated women to demonstrate relaxation approaches in managing breast cancer complaints. This was supported by Wright $(2007)^{[44]}$ who identified an immediate effect of distraction, recreation in stress reduction, and increased relaxation. This complementary therapies are effective for control of symptoms in breast cancer patients who have had an experience of physical and mental problems.

\subsection{Diet and Breast Cancer}

A U-shaped relationship between dietary fat intake and survival following the diagnosis of breast cancer was identified in one observational study suggesting that, extremes in fat intake may be associated with poorer outcomes. Intakes of vegetables, fruit, and related nutrients have been examined in relation to breast cancer recurrence and/or survival in 11 observational studies, with significant protective effects observed in four studies and suggestive findings in two others. ${ }^{[45]}$. In another cohort of breast cancer survivors, consumption of at least five servings per day of fruits and vegetables plus a level of physical activity equivalent to walking 30 minutes 6 days per week was associated with a $50 \%$ reduction in mortality over a7-years follow-up ${ }^{[45]}$.

\section{Conclusion}

Three-weeks PLISSIT counseling model for sexual intervention was effective in enhancing sexual functioning (except in the area of sexual desire or libido), couple satisfaction and body image for women with breast cancer undergoing treatment. PLISSIT counseling intervention play an important role in alleviating side effects related to cancer breast treatment.

\section{Recommendation}

- Adopting PLISSIT counseling Sexual model in addressing sexual dysfunction in a cancer breast treatment institutions.

- Prepare a secure environment in the hospital outpatient units to discuss sexual problems with women freely as well as increasing the number of specialized trained counselor nurses for sex therapy.

- Applying the evidence -based nursing interventions to address and manage the effects of cancer breast and its treatment on sexuality and body image.

- It is important to establish strategies to facilitate the husband's understanding and support the potential impact of treatment related cancer breast on women.

\section{Acknowledgment}

We would like to thank all participated women with breast cancer for her cooperation, patience and interaction. All thanks for Dr / Ehab Shaltout - PhD in Oncology-Oncology Institute, Menoufia University, for helping and supporting in facilitating data collection and counseling process.

\section{References}

[1] WHO. (2015). Breast cancer: prevention and control. available http://www.who.int/cancer/detection/breastcancer/en/ 
[2] Ibrahim, I., Hussein, M., Khaled, N., Mikhail,N.H., Baraka,H., Hossam, K., Amal, S.( 2014). Cancer Incidence in Egypt: Results of the National Population-Based Cancer Registry Program. Journal of Cancer Epidemiology, 2014 (2014), 118.

[3] Coleman, M.P. (2008). Cancer survival in five continents: a worldwide population-based study (CONCORD). Lancet Oncology, 9, 730-56.

[4] Nadine, Z., and Jill Keller.(2009). The importance of assessing sexuality: A patient perspective. Oncology Nursing Society, 13 (2).

[5] Lavin, M., and Hyde, A. (2006). Sexuality as an aspect of nursing care for women receiving chemotherapy for breast cancer in an Irish context. European Journal of Oncology Nursing, 10, 10-18.

[6] Grogan, S. (2008). Body Image: Understanding body dissatisfaction in men, women and children (second edition), New York: Routledge.

[7] Breast cancer support charity. (2014). My body, myself, Altered body image, intimacy and sex after breast cancer.

[8] Hopwood, P., Fletcher, I., Lee, A., Al Ghazal, S.A. (2001). Body image scale for use with cancer patients. European Journal of Cancer, 37, 189-197.

[9] Dixon, K.D.\& Dixon, P.N. (2006). The PLISSIT Model: care and management of patients' psychosexual needs following radical surgery. Lippincotts Case Management, 11(2), 101106.

[10] Mansour, S. E., and Mohamed, H. E. (2015). Handling sexuality concerns in women with gynecological cancer: Egyptian nurse's knowledge and attitudes. Journal of Education and Practice, 6 (3), 146-154.

[11] Government of Western Australia department of health. (2014).Clinical guidelines gynecology; referral to the nurse led sexual wellness.

[12] Rosen, R.(2000). The female sexual function index (FSFI): A multidimensional self-report instrument for the assessment of female sexual function. Journal of Sex and Marital Therapy, 26 (2),191-208.

[13] Crane, D. R., Middleton, K. C., \& Bean, R. A. (2000). Establishing criterion scores for the Marital Satisfaction Scale and the Revised Dyadic Adjustment Scale. American Journal of Family Therapy, 28(1), 53-60.

[14] Nami Chun.(2011). Effectiveness of plissit model sexual program on female sexual function for women with gynecologic cancer. Journal Korean Academic Nursing. 41(4), 471-480.

[15] Dawson, B. D., and Trapp, R. G.(2001). Reading the medical literature: basic \& clinical biostatistics. Lange Medical Book/ McGraw - Hill. Medical Publication Division, New York. 3rd ed., Ch. 7-9, PP 161-218 and Ch. 13, PP 305-314.

[16] Krebs,L.U.(2012). Sexual health during cancer treatment. Advanced Experimental Medical Biology.,732, 61-76.

[17] Gauri, B., Hadeel, A., Sameeksha, B., Cynthia, V., Judie, R., Goodman,S,T.(2014). Impact of breast cancer diagnosis and treatment on sexual dysfunction, Journal of Clinical Oncology., 32.
[18] Abd El-Aziz, N, A., Mersal F, A., Taha,N, M. (2011). Nursing Intervention Program for Early Detection and Prevention of Breast Cancer among Working women, Journal of American Science, 7(1):450-459.

[19] Rapiti E , Fioretta G, Verkooijen, H,M., Vlastos, G., Schäfer, P., Sappino, A,P., Kurtz, J., Neyroud-Caspar, I., Bouchardy, C.(2005).Survival of young and older breast cancer patients in Geneva from 1990 to 2001, European Journal of Cancer., 41(10):1446-52.

[20] Nicoletta, B., Giulia, M., Elisa, P., Paola, S., Riccardo, P. (2010). Effects of surgical and adjuvant therapies for breast cancer on sexuality, cognitive functions, and body weight. International Society for Sexual Medicine, 1-10.

[21] Graziottin, A. (2005). Breast cancer and its effect on women's body image and sexual function. PP276.

[22] Arora, N.K., Gustafson, D.H., Hawkins, R.P., Mctavish, F., Cella, D.F., Pingree, S., Mendenhall, J.H., Mahvi, D.M.(2001) Impact of surgery and chemotherapy on the quality of life of younger women with breast carcinoma: a prospective study. Cancer,92 (5),1288-98.

[23] Bakewell, T. R. \& Volker, D.L. (2005). Sexual dysfunction related to the treatment of young women with breast cancer. Clinical Journal of Oncology Nursing, 9, (6) 697-702.

[24] Shiahna M. Dye. (2008). Factors affecting the impact of breast cancer on body image and sexual functioning, thesis, PP 1-29.

[25] Sbitti,Y.(2010). Breast cancer treatment and sexual dysfunction: Moroccan women's perception. BMC Women's Health. 11:29.

[26] Wilmoth, M.C.(2001). The aftermath of breast cancer: an altered sexual self. Cancer Nursing 24(4),278-86.

[27] Gilbert, E., Ussher, J.M., Perz, J.(2010). Sexuality after breast cancer: a review. Maturitas, 66, 397-407.

[28] Fobair P, Stewart SL, Chang S. (2006). Body image and sexual problems in young women with breast cancer. Psychooncology, 15,579-94.

[29] National breast cancer center (2004). Psychosocial impact in the areas of body image and sexuality for women with breast cancer, 1-67.

[30] Knapstein, S., Fusshoeller, C., Franz, C., Trautmann, K., Schmidt, M., pilch, H., Schoenefuss, G., Kelleher, D., Vavpel, P., Knapstein, P., Koelbl.(2002). The impact of treatment for genital cancer on quality of life and body image-results of a prospective longitudinal 10-years study. U Gynecology U, 94,398-403.

[31] Kissane, D. (2003).The psychosocial impact in the areas of body image and sexuality for women with breast cancer. Camperdown, Australia: National Breast Cancer Centre.

[32] Rogers, M., and Kristjanson, L.J.(2002). The impact on sexual functioning of chemotherapy-induced menopause in women with breast cancer. Cancer Nursing, 25(1):57-65.

[33] Jody Pelusi (2006). Sexuality and Body Image: Research on breast cancer survivors documents altered body image and sexuality. American Journal of Nursing, 106 (3), 32 - 38.

[34] Speer, J.J., Hillenberg, B., Sugrue. (2005). Study of sexual functioning determinants in breast cancer survivors. The Breast Journal, 11;6, 440-447. 
[35] Michael, Y.L.(2000). The persistent impact of breast carcinoma on functional health status: prospective evidence from the Nurses' Health Study. Cancer, 89 (11),2176-86.

[36] Ganz, P.A.(2002). Quality of life in long-term, disease-free survivors of breast cancer: a follow-up study. Journal Nationall Cancer Institute, 94(1),39-49.

[37] Jack, S., Annon, (1976). The PLISSIT model: A proposed conceptual scheme for the behavioral treatment of sexual problems. Journal of Sex Education and Therapy, 2(2), 1-15.

[38] Dizon, D.S.(2009). Quality of life after breast cancer: survivorship and sexuality. Breast Journal, 15,500-4.

[39] Rees, C. E., \& Bath, P. A. (2000). The information needs and source preferences of women with breast cancer and their family members: A review of the literature published between 1988 and 1998. Journal of Advanced Nursing, 31, 833-841.

[40] Engel, J., Kerr, J., Schlesinger-Raab, A., Echkel, R., Sauer, H., \& Hölzel, D. (2003). Comparison of breast and rectal cancer patients' quality of life: Results of a four year prospective field study. European Journal of Cancer Care, 12, 215-223.

[41] North American Menopause Society.(2007). The role of local estrogen for treatment of vaginal atrophy in postmentopausal women: 2007 position statement on the North American Menopause Society, Menopause, 14,355-369.

[42] Stevinson, C., \& Fox, K. R. (2005). Role of exercise for cancer rehabilitation in UK hospitals: A survey of oncology nurses, European Journal of Cancer Care, 14,63-69.

[43] Campbell, A., Mutrie, N., White, F., McGuire, F., Kearney,N. (2005). A pilot study of a supervised group exercise programme as a rehabilitation treatment for women with breast cancer receiving adjuvant treatment. European Journal of Oncology Nursing, 9, 56-63.

[44] Wright, S. A. E. (2007). Effects of massage therapy and touch on quality of life outcomes for autologous stem cell transplant patients. Unpublished master's thesis, University of Virginia,Virginia, USA.

[45] Pierce, J,P., Stefanick, M,L., Flatt, S,W., Natarajan, L., Sternfeld, B., Madlensky, L., Al-Delaimy, W,K., Thomson, C,A., Kealey, S., Hajek, R., Parker, B,A., Newman, V,A., Caan, B., Rock, C,L.(2007). Greater survival after breast cancer in physically active women with high vegetable-fruit intake regardless of obesity. Journal of Clinical Oncology. 25,2345-2351. 